\title{
Attached microalgae contribute to planktonic food webs in bays with fish and pearl oyster farms
}

\author{
Hideyuki Doi ${ }^{1, *}$, Kwang-Hyeon Chang ${ }^{2}$, Yumiko Obayashi ${ }^{2}$, Mizuho Yoshihara ${ }^{1}$, \\ Mary Shime $^{1}$, Takako Yamamoto ${ }^{1}$, Yuichiro Nishibe ${ }^{2}$, Shin-ichi Nakano ${ }^{1}$ \\ ${ }^{1}$ LAFWEDY, Faculty of Agriculture, Ehime University, 3-5-7, Tarumi, Matsuyama 790-8566, Ehime, Japan \\ ${ }^{2}$ Center for Marine Environmental Studies (CMES), Ehime University, Bunkyo-cho 2-5, Matsuyama 790-8577, Japan
}

\begin{abstract}
Planktonic food webs are primarily dependent on organic matter derived from phytoplankton. In coastal areas, aquaculture has accelerated in recent decades, and attached algae and invertebrates proliferate on the farming cages. We hypothesized that the organic material on the farm structures is important to planktonic food webs and that the effects of aquaculture differ between fish (fertilized) and pearl oyster farms (not fertilized). To test these hypotheses, we examined the planktonic food webs at fish and pearl oyster farms using stable isotopes in the Uwa Sea, Japan. We collected zooplankton, particulate organic matter (POM, predominantly phytoplankton), attached algae, and macroinvertebrates in July 2005 and February 2006. Based on the isotope mixing model results, the attached microalgae contributed up to approximately $70 \%$ of the copepod food sources, and the contribution of attached microalgae to cyclopoid copepods was similar to their contribution to attached macroinvertebrates. Amphipods mainly fed on planktonic detritus from microalgae that had detached from the farm structures. The contribution of attached microalgae to copepod biomass was lower on the pearl oyster farm than on the fish farm. Our results show that attached microalgae from sea farms are important food sources for planktonic food webs in areas with fish farms and that the 2 food webs, attached and pelagic, are coupled through zooplankton grazing.
\end{abstract}

KEY WORDS: Zooplankton $\cdot$ Copepod $\cdot$ Phytoplankton $\cdot$ Grazing $\cdot$ Stable isotope $\cdot$ Isotope mixing model $\cdot$ Amphipod $\cdot$ Pelagic food webs

\section{INTRODUCTION}

Components of the planktonic food web primarily depend on phytoplankton (e.g. Hugues et al. 2000, Xu \& Wang 2003). However, food webs are also dependent on inflowing allochthonous matter from streams (Sandberg et al. 2004) and estuaries (Bouillon et al. 2000), and on autochthonous matter from benthic macro- and microalgae on sediment and stones (Kibirige et al. 2002, Takai et al. 2002). Benthic microalgae can be important for both benthic and pelagic food webs in lakes and oceans, because they are coupled through the trophic interactions of zooplankton and grazing fishes (e.g. Schindler \& Scheuerell 2002 in lakes, Takai et al. 2002 in the ocean).
Recently, many fish cultivation farms have been constructed in coastal areas, and a large amount of food is provided to the fish (Black 1998). Fish farms generally enrich surrounding waters and sediments with nutrients and organic matter, and this loading can cause a variety of environmental problems, such as algal blooms and sediment anoxia (e.g. Angel et al. 2002). Fish farm fertilization may cause eutrophication of coastal areas. Farms use many nets and ropes, and large amounts of algae and invertebrates are attached to these structures. Among attached organisms, microalgae may be utilized as food by zooplankton in the surrounding waters. At nutrient-enriched fish farms, the biomass of attached microalgae is 2.5 times higher than that at fish farms with low nutrients, while phytoplankton biomass is only 10 to $30 \%$ higher, prob- 
ably because phytoplankton biomass is influenced by water changes between farms and the sea around farms (Honkanen \& Helminen 2000). Compared to fish farms, pearl oyster farms are not fertilized, but the cages are more structurally complex. Thus, we hypothesized that the attached microalgae on cage structures are important components of planktonic food webs and that the effects of aquaculture differ between fish (fertilized) and pearl oyster (not fertilized, but more complex) farms.

The objective of the present study was to assess the contribution of attached microalgae in farms to planktonic food webs in a coastal area. Our working hypotheses were that (1) the contribution of attached microalgae to planktonic food webs would be higher in the fish farm than in the pearl oyster farm, due to the fertilization of the fish farm, and (2) the contribution of attached microalgae would be observed near farm cages, while the contribution would be lower outside the farms.

To test these hypotheses, we examined the contribution of attached microalgae to planktonic food webs in 2 bays: 1 with a fish farm and 1 with a pearl oyster farm. We analyzed carbon and nitrogen stable isotopes $\left(\delta^{13} \mathrm{C}\right.$ and $\left.\delta^{15} \mathrm{~N}\right)$ to determine the origin and pathways of organic matter. In marine consumers, ${ }^{13} \mathrm{C}$ typically becomes enriched by $0.8 \%$ (France \& Peters 1997) and ${ }^{15} \mathrm{~N}$ by 3 to $4 \%$ (Owens 1987, Wada et al. 1991) relative to their prey. We also compared food webs between the fish and pearl farms, between the summer and winter, and between the farm sites and sites away from the farms.

\section{MATERIALS AND METHODS}

Study area. We conducted our study in Uchiumi $\left(33^{\circ} 02^{\prime} \mathrm{N}, 132^{\circ} 28^{\prime} \mathrm{E}\right)$ and Fukuura Bays $\left(32^{\circ} 55^{\prime} \mathrm{N}\right.$, $132^{\circ} 30^{\prime} \mathrm{E}$ ), which are $14 \mathrm{~km}$ apart in the coastal area of the Uwa Sea, Japan. In Uchiumi Bay, pearl oysters Pinctada fucata martensii are cultured, but fish farm-

Table 1. Environmental factors of the surface waters in Uchiumi Bay (pearl oyster culture, $53 \mathrm{~m}$ depth) and Fukuura Bay (fish culture, $30 \mathrm{~m}$ depth)

\begin{tabular}{|c|c|c|c|c|c|}
\hline & $\begin{array}{l}\text { Temp. } \\
\left({ }^{\circ} \mathrm{C}\right)\end{array}$ & $\begin{array}{c}\text { Chl a } \\
\left(\mu \mathrm{g} \mathrm{l}^{-1}\right)\end{array}$ & $\begin{array}{c}\mathrm{NO}_{2}^{-}+\mathrm{NO}_{3}^{-} \\
\left(\mu \mathrm{mol} \mathrm{l} l^{-1}\right)\end{array}$ & $\begin{array}{c}\mathrm{NH}_{4}^{+} \\
\left(\mu \mathrm{mol} \mathrm{l}^{-1}\right)\end{array}$ & $\begin{array}{c}\mathrm{PO}_{4}^{-} \\
\left(\mu \mathrm{moll}^{-1}\right)\end{array}$ \\
\hline \multicolumn{6}{|c|}{ Uchiumi Stn U } \\
\hline Jul & 23.6 & 1.20 & 0.32 & 0.50 & 0.60 \\
\hline Feb & 16.5 & 1.14 & 2.16 & 1.72 & 0.23 \\
\hline \multicolumn{6}{|c|}{ Fukuura Stn F } \\
\hline Jul & 23.5 & 1.74 & 2.81 & 10.3 & 0.09 \\
\hline Feb & 17.0 & 0.53 & 2.88 & 7.44 & 0.77 \\
\hline
\end{tabular}

ing is rare (Tomaru et al. 2001). Fish are cultured in Fukuura Bay. The water depths at the study sites in Uchiumi and Fukuura Bays are approximately 53 and $30 \mathrm{~m}$, respectively, without inflowing streams. Environmental conditions of the surface water in the bays (Stns U-F and F-F) are shown in Table 1. Water temperature was measured with a Chlorotech profiler (ACL-208-DK, Alec Electronics). Chlorophyll a was measured using a fluorometer (10-AU, Turner Designs), following extraction using GF/F filters with $\mathrm{N}, \mathrm{N}$-dimethylformamide. Nutrient concentrations were determined by colorimetric analysis with a continuous flow system (AutoAnalyzer 3, BRAN+ LUEBBE).

Sampling and preparations. Zooplankton, particulate organic matter (POM, predominantly phytoplankton), attached microalgae, and attached macroinvertebrates were sampled in summer (12 and 27 July 2005) and winter (10 and 21 February 2006). We sampled approximately $2 \mathrm{~m}$ from the cage structures at farms in Uchiumi and Fukuura Bays (Stns U-F and F-F). In February, we collected samples at both of these stations and at off-farm sites (Stns U-OF and F-OF) that were approximately $300 \mathrm{~m}$ from the nearest farm cages (Fig. 1).

We collected $1 \mathrm{l}$ surface water samples $(\mathrm{n}=4)$ at each site to collect POM samples, because the carbon isotope values of POM at 0 and $15 \mathrm{~m}$ depth were not significantly different in either bay (Y. Matsuzawa unpubl. data). The collected water was filtered through Whatman GF/F glass-fiber filters (precombusted at $500^{\circ} \mathrm{C}$ for $2 \mathrm{~h}$ ). Zooplankton remaining on the filter was removed. POM samples were treated with $1 \mathrm{~mol} \mathrm{l}^{-1} \mathrm{HCl}$ to remove inorganic carbon prior to isotope measurements. Zooplankton were collected vertically from 0 to $20 \mathrm{~m}$ depth with a $200 \mu \mathrm{m}$ mesh plankton net and sorted and put into a tip cup under a stereomicroscope (3 or 4 replicates). We randomly collected microalgal mat, hyperiid amphipods, and Caprella spp. (skeleton shrimp, Caprellidae), which were attached to and lived on the cotton ropes at the farms, by hand from 0 to $1 \mathrm{~m}$ depth. To collect attached microalgae, we removed any macroinvertebrates by the microalgal mat, and then the microalgal mat was filtered through Whatman GF/F glass-fiber filters (precombusted at $500^{\circ} \mathrm{C}$ for $2 \mathrm{~h}$ ) and treated with $1 \mathrm{~mol} \mathrm{l}^{-1}$ $\mathrm{HCl}$ to remove inorganic carbon prior to isotope measurements. Attached microalgae consisted mainly of filamentous microalgae. The bays have no inflow and are relatively deep ( 30 and $53 \mathrm{~m}$ mean depth). Thus, the potential food sources to zooplankton from terrestrial and benthic habitats may be negligible.

Stable isotope measurements. The isotope ratios of copepods, amphipods, and Caprella spp. were measured using whole bodies of 10 to 100,1 to 2 , and 2 to 


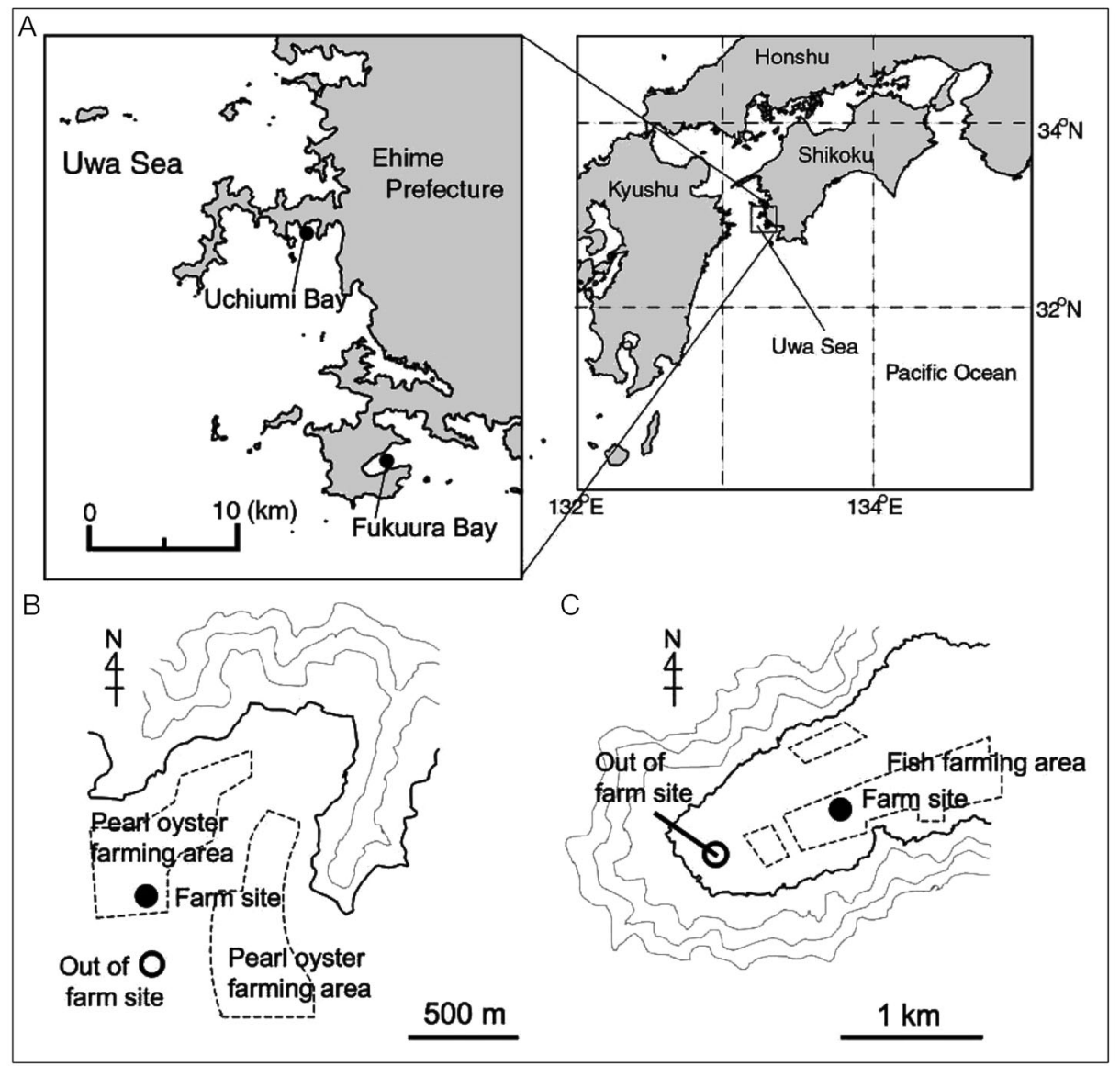

Fig. 1. (A) Maps of the sampled bays (Uchiumi Bay and Fukuura Bay) in the Uwa Sea, Japan. Sampling stations in (B) Uchiumi Bay and $(\mathrm{C})$ Fukuura Bay are also shown

5 ind. per sample, respectively. The carbon and nitrogen isotope ratios of the samples were measured with an elemental-analyzer continuous flow mass spectrometer (Integra CN, SerCon). The results are reported in delta notation: $\delta^{13} \mathrm{C}$ or $\delta^{15} \mathrm{~N}=\left(R_{\text {sample }} / R_{\text {standard }}-1\right)$ 1000 (\%), where $R$ is the ${ }^{13} \mathrm{C} /{ }^{12} \mathrm{C}$ or ${ }^{15} \mathrm{~N} /{ }^{14} \mathrm{~N}$ ratio for $\delta^{13} \mathrm{C}$ or $\delta^{15} \mathrm{~N}$, respectively. PeeDee Belemnite was used as the standard for $\delta^{13} \mathrm{C}$, and air $\mathrm{N}_{2}$ gas was used as the standard for $\delta^{15} \mathrm{~N}$. The analysis errors of reproducibility were within $\pm 0.2 \%$ for both $\delta^{13} \mathrm{C}$ and $\delta^{15} \mathrm{~N}$.

Isotope mixing model. To determine which of the 2 food sources (POM or attached microalgae) were assimilated more readily by macroinvertebrates, we calculated 2-source isotope mixing models. The carbon isotope values of POM and attached microalgae significantly differed from each other by both season and bay (see 'Results'). A carbon isotope fraction for macroinvertebrates of $0.8 \%$ o was used for the model (France \& Peters 1997). The model is defined as:

$$
\begin{gathered}
\delta^{13} \mathrm{C}_{\mathrm{m}}=f_{\mathrm{p}}\left(\delta^{13} \mathrm{C}_{\mathrm{p}}+0.8\right)+f_{\mathrm{a}}\left(\delta^{13} \mathrm{C}_{\mathrm{a}}+0.8\right) \\
f_{\mathrm{p}}+f_{\mathrm{a}}=1
\end{gathered}
$$

where the subscripts $m, p$, and a refer to the $\delta^{13} \mathrm{C}$ of the macroinvertebrate sample, the POM, and the attached microalgae, respectively; $f_{\mathrm{p}}$ and $f_{\mathrm{a}}$ are the contributions of POM and attached microalgae to macroinvertebrate biomass, respectively. To determine the sensitivity of isotope fractionation in the mixing model, we calculated the mixing model with +0.3 and $+1.3 \%$. The variations in models for each species were within $\pm 6.2 \%$ for the different fractions. Carbon isotope values of Temora spp. and Acartia spp. did not lie between these 2 food sources; we estimated that the species consumed exclusively POM, which has an isotopic value identical to the consumer.

Statistical analyses. We used Student's $t$-tests and 1-way analyses of variance (ANOVAs) to test for significant differences in the carbon and nitrogen isotope values of attached microalgae, POM, and macroinvertebrates. For the mixing model results, we used repeated-measures (rm) 2-way ANOVA to examine differences in the contribution of attached microalgae to zooplankton and attached macroinvertebrates between bays (Uchiumi and Fukuura), seasons (sum- 


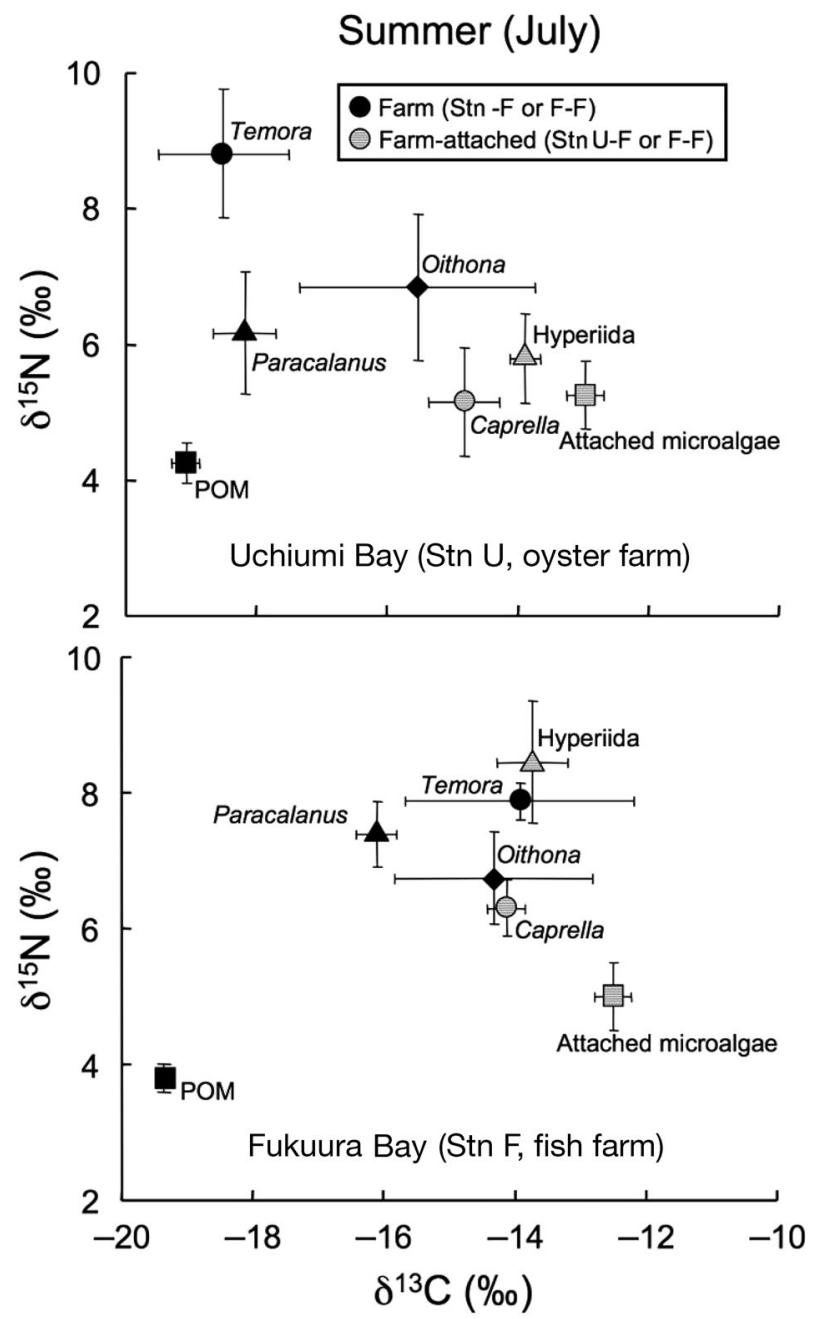

Fig. 2. Carbon and nitrogen isotope plots of samples from Uchiumi and Fukuura Bays in July. Each symbol represents the mean; error bars $= \pm 1$ SD $(n=3$ or 4$)$

mer [July] and winter [February]), and stations (-F and -OF). We used separate rm 2-way ANOVAs to examine the contributions to the zooplankton and attached macroinvertebrates because the attached macroinvertebrates inhabited farm structures, and we considered them to be references for the contribution of attached microalgae to the zooplankton.

\section{RESULTS}

\section{Carbon and nitrogen isotopes of POM and attached microalgae}

The $\delta^{13} \mathrm{C}$ values of attached microalgae (-17.9 to $-12.5 \%$ ) were significantly higher than those of POM $(-25.3$ to $-19.1 \%)$ at all stations in both bays and in both seasons (Student's $t$-tests, $t=3.5$ to $11.8, \mathrm{p}<0.006$, $\mathrm{n}=4$; Figs. $2 \& 3$ ), probably because attached microalgae promote ${ }^{13} \mathrm{C}$-enrichment, due to their supply of dissolved inorganic carbon (DIC), which is limited by the microalgal boundary layer and the thick algal mat (France 1995, Doi et al. 2003). $\delta^{13} \mathrm{C}$ values of POM were not significantly different between Stns U-F and U-OF $(t=-0.1, \mathrm{p}=0.933)$, but were significantly higher at Stn F-F than at Stn F-OF ( $t=-3.9, \mathrm{p}=0.017$; Fig. 3).

In both bays, the $\delta^{13} \mathrm{C}$ values were significantly higher in July than in February for both attached microalgae $(t=-2.7$ and $-12.5, \mathrm{p}=0.045$ and $<0.001$ for Uchiumi and Fukuura, respectively) and POM ( $t=$ -7.25 and $-7.24, p=0.002$; Fig. 3). High water temperature affects the photosynthesis activity and isotope fractionation of microalgae (Fry 1996). Thus, the attached and planktonic microalgae in summer promoted ${ }^{13} \mathrm{C}$-enrichment, because the supply of DIC

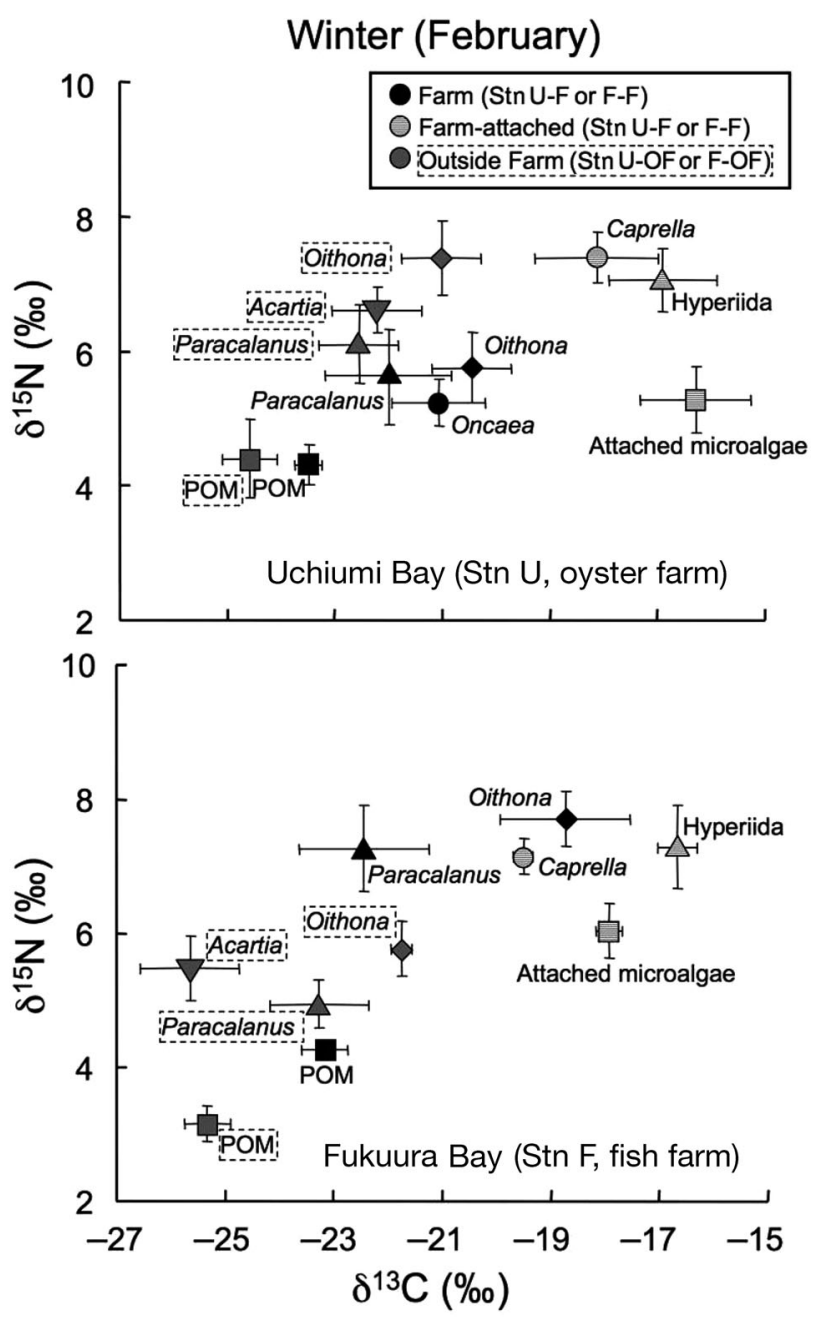

Fig. 3. Carbon and nitrogen isotope plots of samples from Uchiumi and Fukuura Bays in February. Each symbol represents the mean; error bars $= \pm 1$ SD ( $\mathrm{n}=3$ or 4 ) 
is limited by the thick algal mat and the low carbon isotope fraction (Fry 1996, Doi et al. 2003).

\section{Carbon and nitrogen isotopes of planktonic and attached macroinvertebrates}

In Uchiumi and Fukuura Bays, the copepods Oithona spp. (Cyclopoida) and Paracalanus spp. (Paracalanidae) dominated our samples. We also collected Temora spp. (Temoridae) in July and Acartia spp. (Acartiidae) in February in both bays, and Onacea spp. (Oncaeidae) in February in Uchiumi Bay (Figs. 2 to 4).
Table 2. Two-way ANOVA results for contribution of attached microalgae to the macroinvertebrates

\begin{tabular}{|lcc|}
\hline Factor & $F$ & $p$ \\
\hline Attached invertebrates & & \\
Seasons & 0.01 & 0.918 \\
Bays & 0.56 & 0.462 \\
Seasons $\times$ Bays & 0.24 & 0.567 \\
Zooplankton & & \\
Seasons & 0.02 & 0.89 \\
Bays & 7.63 & 0.01 \\
Seasons $\times$ Bays & 1.77 & 0.19 \\
\hline
\end{tabular}

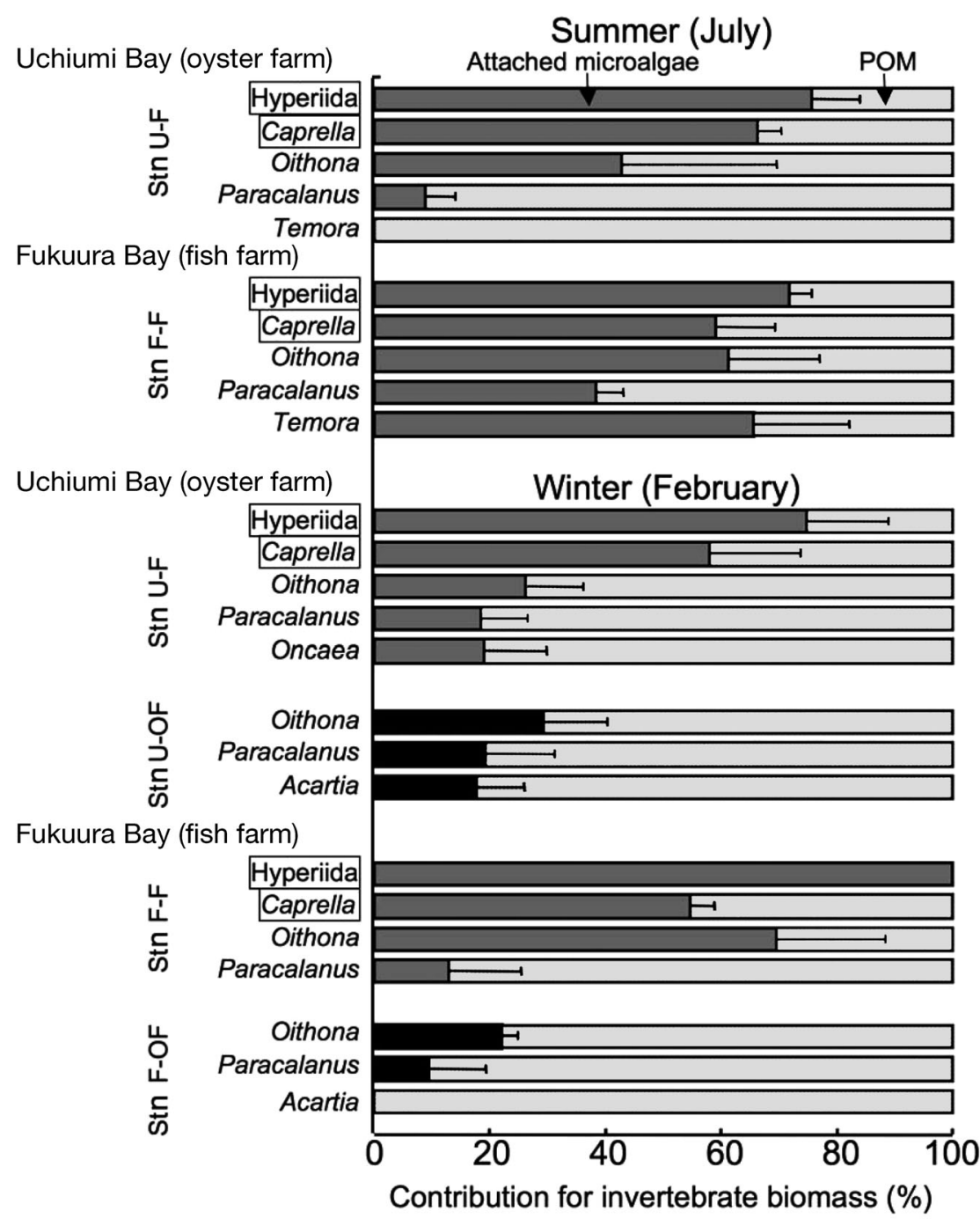

Fig. 4. Contribution of attached microalgae (mean $\pm 1 \mathrm{SD}, \mathrm{n}=3$ or 4 ) to the macroinvertebrates at Stns F (farm, dark grey bars) and OF (outside farm, black bars) in Uchiumi and Fukuura Bays in both seasons. Amphipods (Hyperiida) and Caprella spp. were collected from farm structures (within rectangles). Variations in models for each species were within $\pm 6.2 \%$ for the different isotope fractionations (see 'Materials and methods')
The stable isotope ratios of other zooplankton taxa could not be measured, because it was difficult to obtain enough biomass for the analysis.

In both bays, the $\delta^{13} \mathrm{C}$ values of macroinvertebrates in July were significantly higher than those in February (ANOVA, $F=37.4, p<0.001$ ), matching the seasonal changes in $\delta^{13} \mathrm{C}$ values of POM and attached microalgae. Changes in the $\delta^{13} \mathrm{C}$ values of macroinvertebrate species among seasons and stations were observed (Figs. 2 \& 3). These $\delta^{13} \mathrm{C}$ values of macroinvertebrates indicated 2 possibilities: shifts in the composition of their food sources or a reflection of seasonal and spatial changes in the $\delta^{13} \mathrm{C}$ values of POM and attached microalgae. Thus, in the present study, we estimated differences in the food sources of the macroinvertebrates by analyzing contribution ratios.

\section{Contribution of attached microalgae to macroinvertebrate biomass}

Attached macroinvertebrates, hyperiid amphipods, and Caprella spp. mainly depended on attached microalgae as their food source in both bays and both seasons (Fig. 4, Table 2). The mean contribution of attached microalgae to zooplankton species varied from $0.0 \%$ (Acartia spp. and Temora spp.) to $69.5 \%$ (Oithona spp.; Fig. 4). The contribution of attached micro-algae to zooplankton was significantly higher in Fukuura Bay than in Uchiumi Bay (Table 2). 
In July, Oithona spp. tended to depend on materials from attached microalgae in both bays. The contribution of attached microalgae to Paracalanus spp. and Temora spp. in Fukuura Bay (38.4 to $66.7 \%$ ) was significantly higher than in Uchiumi Bay (0.0 to 8.8\%; Paracalanus spp.: $t=6.65$, $\mathrm{p}=0.002$; Temora spp.: $t=-4.45$, $\mathrm{p}=0.006$, $\mathrm{n}=4$ ). In February, the contribution of microalgae to Oithona spp. was significantly higher at Stn F-F than at Stn U-F ( $t=-2.23, \mathrm{p}=0.034)$. The contribution of microalgae to Paracalanus spp. was $<20 \%$ and did not differ between bays $(t=0.745, \mathrm{p}=0.497)$. The contribution of microalgae to Oithona spp. was significantly higher at Stn F-F than at Stn F-OF $(t=-4.42, \mathrm{p}=0.011)$.

\section{DISCUSSION}

Our results show that the contribution of attached microalgae was up to approximately $70 \%$ of the copepod biomass in Fukuura Bay. Thus, copepods largely depended on materials from attached microalgae as their food source. Attached microalgae formed the basis of the planktonic food web, but their contribution depended on the type of farming, i.e. fish versus oyster farms. Farm cages were constructed of nets and ropes, which may provide a large interface between the water and the cage surfaces, and may explain the higher contribution of attached microalgae on the fish farm than in the estuary.

The contribution of attached microalgae to Oithona spp. in both bays and to Temora spp. in Fukuura Bay is similar to the contribution to hyperiid amphipods and to Caprella spp. in Fukuura Bay, although the copepods are all planktonic. There are 2 hypotheses for why planktonic copepods feed on farm-attached microalgae. The first is that the copepods feed directly on attached microalgae, as do amphipods and Caprella spp. Conover et al. (1986) suggested that the arctic copepod Pseudocalanus spp. may feed opportunistically near the ice-water interface, perhaps directly on algae attached to the ice. However, in that case, the copepods inhabited a narrow layer at the ice-water interface. We did not observe copepods aggregated near or attached to the ropes, where we collected attached macroinvertebrates, in either bay. Thus, this hypothesis may be inappropriate for copepods whose main food items were attached microalgae. The second hypothesis is that the copepods feed on planktonic detritus from attached microalgae. In marine environments, sources of detritus are diverse and include nonliving phytoplankton, fecal material, carcasses and molts of zooplankton, and resuspended sediments (Roman 1984). The concentration of detritus in the coastal marine environment is generally greater than the living phytoplankton biomass (Bouillon et al. 2000).
Many studies have demonstrated the importance of detritus as a food source for zooplankton (e.g. Roman 1984, Xu \& Wang 2002). Thus, copepods near the farm may have fed on planktonic detritus from attached microalgae, while copepods away from the farm fed mainly on phytoplankton-derived POM.

Benthic-pelagic habitat coupling occurs in aquatic ecosystems; primary productivity is transported across food webs through fish and zooplankton (e.g. Kibirige et al. 2002 in an estuary, Schindler \& Scheuerell 2002 in lakes, Takai et al. 2002 in the ocean). The present study shows that materials from attached microalgae play an important role in planktonic food webs in sea farm habitats. Thus, the farm-attached and planktonic food webs may be coupled with each other through the zooplankton community, especially in the summer.

In Fukuura Bay, the attached algal contribution to the planktonic food web was higher than that in Uchiumi Bay, probably because the fish farms in Fukuura Bay were fertilized. Thus, the eutrophication of coastal marine areas caused by fertilization may modify pelagic food web structure, especially the base of the food web. Copepods are important prey items for fish, and their fecal pellets sink. Thus, the eutrophication induced by fish farming might affect other fish and the material transport system of the ecosystem through copepods. In addition, in this study, the OF stations were comparatively less affected by farm-attached microalgae. However, fish farms have rapidly proliferated along the coast in recent decades. Our results clearly show that eutrophication can modify pelagic food web structure. However, the present study is just an initial step in estimating the effect of aquaculture on microalgal-zooplankton trophic connections-we did not estimate the effect of such trophic connections on the whole food web. Further study of the whole food web is necessary to protect and preserve coastal marine environments.

Acknowledgements. We thank K. Hyodo, T. Hirose, and the staff of Uchiumi Institute of Oceanic and Fishery Science, and the students of Ehime University, A. Kihara, M. Kono, and Y. Matsuzawa for their help in field monitoring. The present study was partly supported by the Grant-in-Aid for Scientific Research No.16201004, JSPS, the Research Fund for the coastal environment in Uchiumi Bay, Uchiumi Village, Ehime Prefecture, Center of Excellence (COE) Program at the 'Global Center of Excellence for Interdisciplinary Studies on Environmental Chemistry', and JSPS to H.D.

\section{LITERATURE CITED}

Angel DL, Eden N, Breitstein S, Yurman A, Katz T, Spanier E (2002) In situ biofiltration: a means to limit the dispersal of effluents from marine finfish cage aquaculture. Hydrobiologia 469:1-10 
Black KD (1998) The environmental interactions associated with fish culture. In: Black KD, Pickering AD (eds) The biology of farmed fish. Sheffield Academic Press, Sheffield, p 284-326

Bouillon S, Chandra Mohan P, Sreenivas N, Dehairs F (2000) Sources of suspended matter and selective feeding by zooplankton in an estuarine mangrove ecosystem, as traced by stable isotopes. Mar Ecol Prog Ser 208:79-92

Conover RJ, Herman AW, Prinsenberg SJ, Harris LR (1986) Distribution of and feeding by the copepod Pseudocalanus under fast ice during the arctic spring. Science 232: 1245-1247

Doi H, Kikuchi E, Hino S, Itoh T, Takagi S, Shikano S (2003) Seasonal dynamics of carbon stable isotope ratios of particulate organic matter and benthic diatoms in strongly acidic Lake Katanuma. Aquat Microb Ecol 33:87-94

France RL (1995) Cabon-13 enrichment in benthic compared to planktonic algae: food webs implications. Mar Ecol Prog Ser 124:307-312

France RL, Peters RH (1997) Ecosystem differences in the trophic enrichment of ${ }^{13} \mathrm{C}$ in aquatic food webs. Can J Fish Aquat Sci 54:1255-1258

Fry B (1996) ${ }^{13} \mathrm{C} /{ }^{12} \mathrm{C}$ fractionation by marine diatoms. Mar Ecol Prog Ser 134:283-294

Honkanen T, Helminen H (2000) Impacts of fish farming on eutrophication: comparisons among different characteristics of ecosystem. Int Rev Gesamten Hydrobiol 85: $673-686$

Hughes JE, Deegan LA, Peterson BJ, Holmes RM, Fry B (2000) Nitrogen flow through the food web in the oligo-

Editorial responsibility: Matthias Seaman (Assistant Editorin-Chief), Oldendorf/Luhe, Germany haline zone of a New England estuary. Ecology 81: 433-452

Kibirige I, Prerissinotto R, Nozais C (2002) Alternative food sources of zooplankton in a temporarily-open estuary: evidence from $\delta^{13} \mathrm{C}$ and $\delta^{15} \mathrm{~N}$. J Plankton Res 24: 1089-1095

Owens NJP (1987) Natural variations in ${ }^{15} \mathrm{~N}$ in the marine environment. Adv Mar Biol 24:390-451

Roman MR (1984) Utilization of detritus by the copepod Acartia tonsa. Limnol Oceanogr 29:949-959

Sandberg J, Andersson A, Jahansson S, Wikner J (2004) Pelagic food web structure and carbon budget in the northern Baltic Sea: potential importance of terrigenous carbon. Mar Ecol Prog Ser 268:13-29

Schindler DE, Scheuerell MD (2002) Habitat coupling in lake ecosystems. Oikos 98:177-189

Takai N, Mishima Y, Yorozu A, Hoshika A (2002) Carbon sources for demersal fish in the western Seto Inland Sea, Japan, examined by $\delta^{13} \mathrm{C}$ and $\delta^{15} \mathrm{~N}$ analysis. Limnol Oceanogr 47:730-741

Tomaru Y, Kawabata Z, Nakano S (2001) Mass mortality of the Japanese pearl oyster Pinctada fucata martensii in relation to water temperature, chlorophyll $a$ and phytoplankton composition. Dis Aquat Org 44:61-68

Wada E, Mizutani H, Minagawa M (1991) The use of stable isotopes for food web analysis. Crit Rev Food Sci Nutr 30: 361-371

Xu Y, Wang W (2002) The assimilation of detritus-bound metals by the marine copepod Acartia spinicauda. Limnol Oceanogr 47:604-610

Submitted: March 16, 2007; Accepted: August 3, 2007

Proofs received from author(s): December 14, 2007 